\title{
Erratum to: Intersegmental coordination scales with gait speed similarly in men and women
}

\author{
John W. Chow ${ }^{1}$ Dobrivoje S. Stokic ${ }^{1}$
}

Published online: 25 April 2016

(C) Springer-Verlag Berlin Heidelberg 2016

\section{Erratum to: Exp Brain Res (2015) 233:3175-3185 DOI 10.1007/s00221-015-4386-6}

In the original publication, the authors have mistakenly presented the range of motion of hip during the stance and swing phases as the range of motion of knee and ankle, respectively (Fig. 2c-f). Because range of motion data was included as supplemental information (i.e., not used in the hypothesis testing), none of the conclusion were affected. The corrected Fig. 2 is provided below, and the updated Online Resource 2 is available online.

The online version of the original article can be found under doi:10.1007/s00221-015-4386-6.

Electronic supplementary material The online version of this article (doi:10.1007/s00221-016-4652-2) contains supplementary material, which is available to authorized users.

John W. Chow

jchow@mmrcrehab.org

1 Center for Neuroscience and Neurological Recovery,

Methodist Rehabilitation Center, 1350 East Woodrow Wilson

Drive, Jackson, MS 39216, USA 
Fig. 2 Individual (thin) and aggregate (thick) linear regression plots between joint range of motion (left two columns) and range of elevation angle (right 2 columns) against normalized speed. Values on each plot (left to right) are the regression coefficient (slope), coefficient of determination $\left(R^{2}\right)$, and $P$ value $(\leq 0.01$ in bold $)$ for the aggregate slope. The percentage of significant slopes and the percentage of positive/ negative slopes are given inside each square bracket. Vertical dashed lines indicate the average normalized speed at each pace across all subjects
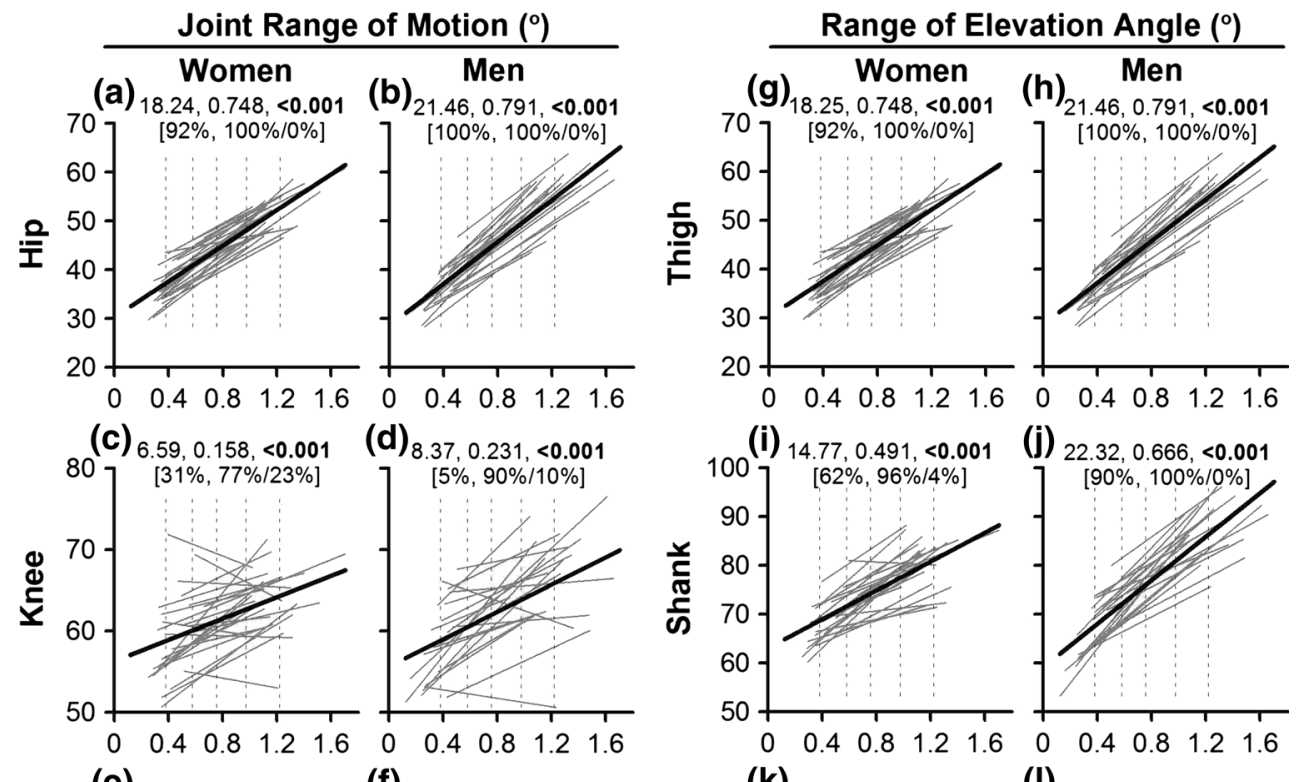

(e) $3,0.026,<0.001$

(d) $8.37,0.231,<0.001$
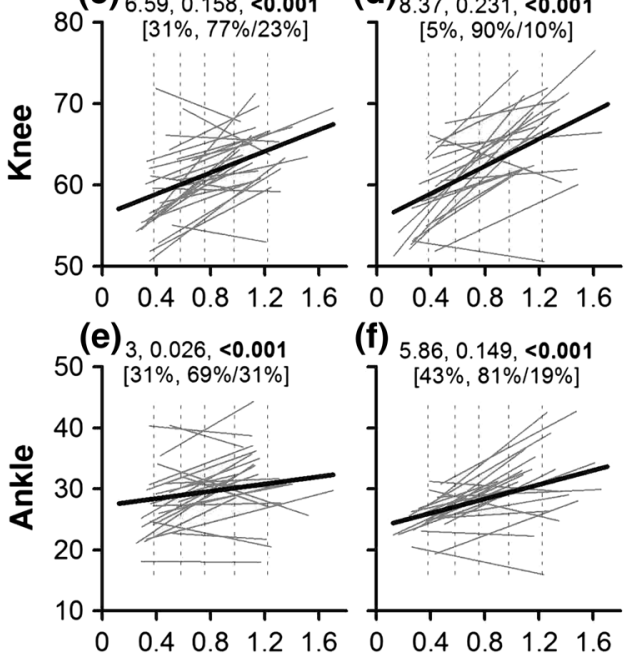

(f) 5

(k)

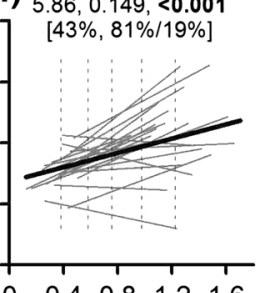

(I) $38.33,0.642,<0.001$

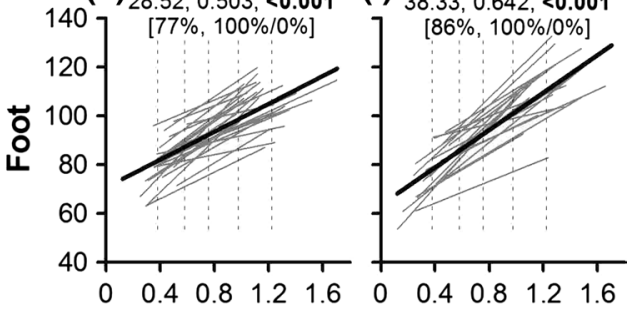

Gait Speed (Body Height/s) 